\title{
ПРОБЛЕМЫ И ПЕРСПЕКТИВЫ РАЗВИТИЯ СИСТЕМЫ ГОСУДАРСТВЕННОГО СТРАТЕГИЧЕСКОГО ПЛАНИРОВАНИЯ В УСЛОВИЯХ ЦИФРОВОЙ ЭКОНОМИКИ
}

\author{
(C) 2021 Бурцева Татьяна Александровна \\ доктор экономических наук, профессор \\ Российский технологический университет - МИРЭА, Россия, Москва \\ E-mail: tbur69@mail.ru
}

(c) 2021 Ахмадов Аслан Русланович

главный специалист-эксперт отдела планирования и прогнозирования бюджета

Министерство финансов Чеченской Республики, Россия, Грозный

E-mail:mr.ahmadov.a@mail.ru

\section{(C) 2021 Сатуев Бекхан Бексолтович}

проректор по стратегическому развитию и социальной работе

Чеченский государственный университет, Россия, Грозный

E-mail:satuev@mail.ru

Актуальность темы связана с необходимостью поиска новых факторов и резервов экономического роста в России. Внутренний рынок является одним из таких факторов. Для его развития в современных условиях необходима эффективная система государственного планирования. В статье рассматриваются проблемы системы государственного стратегического планирования России и предлагаются перспективы их решения в условиях цифровой экономики, которые позволят повысить её эффективность.

Ключевые слова: Экономика, система іМониторинга, прогнозирование, стратегическое планирование, перспективы развития, цифровизация.

\section{ВВЕДЕНИЕ}

Государственное прогнозирование и стратегическое планирование являются рыночными механизмами, которые эффективно работают во многих странах мира, например, США, Канада и ЕС. Эффективная система государственного стратегического планирования предполагает, что в государственной системе управления страны и регионов внедрена система контроля за целевым использованием бюджетных ресурсов и бюджетные денежные потоки используются целевым образом, то есть способствуют экономическому росту, обеспечению занятости трудоспособного населения, реализации национальных проектов в полном объёме.

Развитие мировой экономики сегодня идёт за счёт развития транснациональных корпораций, для которых важно не максимизировать прибыль, а наращивать объёмы продаж [5]. Поэтому для обеспечения социально-экономического развития страны в целом новыми управленческими функциями государства стали стратегическое планирование и прогнозирование, особенно в приоритетных направлениях развития, об этом неоднократно заявлял президент России В.В.Путин в посланиях к Федеральному собранию и указах, определяя стратегические приоритеты развития страны и целевые их ориентиры. Однако, многие правильные и важные для развития страны посылы не были полностью реализованы, что связано, по мнению авторов, с распространённым сегодня ситуационным государственным управлением и неэффективностью существующей в России системой государственного планирования. Целью данной статьи является анализ проблем и поиск перспектив развития системы государственного планирования, которые связаны с формированием в России цифровой экономики.

За последние 15 лет международные потоки ресурсов выросли для информации и информационных технологий на $70 \%$, для миграции $20 \%$, для капитала и товаров на 5-7\% [16, с.2]. Цифровизация экономики принимает доминирующее положение в ряду факторов развития в мире: «7,7 млрд. поисковых запросов осуществляется 
в Google, около 152 млн. звонков производится в Skype, 58 млн. сообщений размещается в Twitter, 36 млн. покупок совершается вAmazon и 2,3 млрд. гигабайт информации курсирует в сети Интернет. Каждую минуту, каждый день отправляется 204 млн. электронных писем, 2,4 млн. постов размещается в Facebook, 72 часа видео выкладывается на Youtube и 216 тыс. фото размещается в Instagram. Каждый год количество цифровых данных увеличивается на 50\%» [15]. Цифровизация влечёт сокращение транзакционных издержек поиска информации, так как в их структуре исчезают издержки на поиск информации и ведение переговоров, что приводит к созданию новых форм бизнеса и управления. Формирование цифровой экономики способствует повышению экономической связности регионов и уменьшению уровня их социальноэкономического неравенства [3]. Потенциальный эффект для валового внутреннего продукта России от цифровизации экономики к 2025 г. оценивается в 4,1-8,9 трлн. р., что составляет 19-34\% общего увеличения ВВП [14]. Эксперты отмечают, что «потенциальные источники прироста ВВП в этом случае:

- оптимизация производственных и логистических операций,

- повышение эффективности рынка труда,

- повышение производительности оборудования,

- повышение эффективности НИОКР и разработки продуктов,

- снижение расхода ресурсов и производственных потерь» [1, с. 93].

Президентом Российской Федерации В.В.Путиным поставлена задача запуска масштабной системной программы развития цифровой экономики в России до 2035 года. [7] Реализация программы цифровой экономики имеет целью формирование полноценной цифровой среды [9]. Именно «цифровизация» экономики позволит России решить вопросы глобальной конкурентоспособности и национальной безопасности, обеспечит рост качества государственного и корпоративного управления. Уже разработана стратегия развития Росстата до 2024 г. [11]. В данной стратегии определено, что ключевым инструментом цифровизации будет цифровая аналитическая платформа (ЦАП) часть Национальной системы управления данными, которая охватит все органы власти, работающие со статистикой, что обеспечит решение проблем дублирования информации, неточности информации, расхождения информации в разных источниках.

ПРОБЛЕМЫ СИСТЕМЫ ГОСУДАРСТВЕННОГО СТРАТЕГИЧЕСКОГО ПЛАНИРОВАНИЯ РОССИИ

Экспертами отмечается, что в России «отсутствует эффективная комплексная государственная система стратегического планирования развития экономики», что является основной причиной отставания России от динамично развивающихся экономик других стран, например, Китая [4, с. 6]. Для формирования единой системы стратегического планирования на федеральном уровне принят ряд документов в области долгосрочного стратегического планирования. Принятие федерального закона «О государственном стратегическом планировании в Российской Федерации» [13] позволило упорядочить систему стратегического планирования и определить единые типы и стандарты подготовки стратегических документов, поэтому можно сказать, что закон обобщил и закрепил формы планирования, которые уже есть. Разработка документов: «Концепция долгосрочного социально-экономического развития Российской Федерации на период до 2020 года», «Стратегия национальной безопасности Российской Федерации до 2020 года», «Основы стратегического планирования в Российской Федерации», «Стратегия пространственного развития российской Федерации до 2025г», стала важной часть работы по формированию системы стратегического планирования и прогнозирования. К сожалению, это не позволило обеспечить эффективное функционирование системы государственного стратегического планирования и прогнозирования России, что во многом снизило перспективы нашей страны по ускорению экономического роста и повышению экономической безопасности.

Причинами неэффективности системы государственного планирования и прогнозирования экономики являются:

- обилие разрозненных ведомственных и отраслевых стратегий и программ, которые часто вступают в противоречие между собой, не согласованы по срокам и целям развития, только на федеральном уровне существует более 500 различных документов стратегического характера; 
- не оправдано завешенное значение прогнозов для реализации экономической политики, превышение роли государственного прогнозирования над государственным планированием, что ведёт к снижению ответственности органов государственного управления за их реализацию, так как прогноз не является обязательным для выполнения и всегда может быть реализован не в полном объёме из-за неопределённости внешней среды;

- отсутствие единства количественно измеримых целей и перспектив развития в государственной экономической политике, которые представлены многочисленными прогнозами (стратегический прогноз развития РФ, прогноз социально-экономического развития РФ, прогноз научно-технологического развития РФ, НТИ, бюджетный прогноз РФ и т.д.);

- отсутствие в стратегических документах характеристики способов и средств достижения стратегических целей устойчивого развития России и обеспечения национальной безопасности, хотя в Указе Президента 2009 г. № 536 «Об основах стратегического планирования в Российской Федерации» прямо говорится о необходимости их наличия;

- отсутствие ведомства, которое отвечает за хронологическое взаимоувязывание стратегических документов, организацию их мониторинга, аудита и актуализацию;

- отсутствие национальной статистической системы, обеспечивающей единство информации и отсутствие её дублирования, а также обеспечивающей требуемое качество официальной статистической информации;

- несогласованность по целям и срокам реализации стратегических документов федерального, регионального и муниципального уровней;

- отсутствие стратегических документов развития федеральных округов, хотя согласно п. 31 «Основ стратегического планирования в Российской Федерации», стратегии социально-экономического развития федеральных округов, наряду со стратегиями социальноэкономического развития субъектов РФ, являются основными документами стратегического планирования на региональном уровне [12, с. 7].

Всвязи с чем представляется необходимым формирование системы стратегических целей развития страны, согласованных с национальными экономическим интересами России, координация стратегических целей с бюджетными возможностями и друг с другом. Поэтому актуальна разработка системы генеральных целей развития страны на срок не менее пяти лет. Также требуется создание единого государственного центра планирования на федеральном уровне, кроме того требуется внедрение новых требований к квалификации и опыту кадров, жёстких механизмов ответственности за достижение целевых показателей. В этой связи интересен опыт республики Беларусь, правда, это касается только федерального уровня управления [6, с. 61].

ПЕРСПЕКТИВЫ РАЗВИТИЯ СИСТЕМЫ ГОСУДАРСТВЕННОГО СТРАТЕГИЧЕСКОГО ПЛАНИРОВАНИЯ В УСЛОВИЯХ ЦИФРОВОЙ ЭКОНОМИКИ РОССИИ

Система стратегического планирования России - совокупность основных направлений, способов и средств достижения стратегических целей устойчивого социально-экономического развития страны и обеспечения её национальной безопасности. Для развития системы государственного планирования необходимо провести аудит стратегических документов федерального уровня управления. Далее провести их согласование с региональными и муниципальными стратегическим документами. Для реализации аудита необходимо разработка генеральных целей устойчивого развития страны, в качестве которых могут выступать национальные цели, обозначенные Указом Президента Российской Федерации от 21 июля 2020 г. N 474 «О национальных целях развития Российской Федерации на период до 2030 года»:

a) сохранение населения, здоровье и благополучие людей;

б) возможности для самореализации и развития талантов;

в) комфортная и безопасная среда для жизни;

г) достойный, эффективный труд и успешное предпринимательство;

д) цифровая трансформация.

В рамках каждой цели установлены целевые показатели, характеризующие ее достижение в 2030 году. Ситуация с коронавирусной инфекцией требует их корректировки. Уже сформирован проект единого плана по достижению национальных целей развития Российской Федерации на период до 2024 года и на плановый период до 2030 [10]. Он определяет стратегические приоритеты Правительства Российской Федерации 
по реализации национальных целей развития на ближайшие 10 лет. Реализация данного плана должна обеспечить рост доходов населения и экономический рост в экономике России.

В проекте прописана персональная ответственность за реализацию плана. На федеральном уровне она возлагается на заместителей Председателя Правительства Российской Федерации. На региональном уровне ответственность возлагается на губернаторов, а главы органов местного самоуправления несут ответственность за реализацию национальных целей в муниципальных образованиях. Показатели достижения национальных целей для субъектов Российской Федерации будут устанавливаться в едином плане, тем самым реализуется принцип единства планирования. Механизм управления достижением национальных целей развития предполагает также сочетание стратегического видения и достаточной оперативной гибкости. Единый план содержит только верхнеуровневую систему показателей и основные комплексы мероприятий. Детализация задач, мероприятий, инструментов, а также индикаторов содержится в национальных проектах и государственных программах. Для повышения эффективности управления порядок формирования, исполнения и контроля государственных программ будет меняться. Предполагается, что данные документы будут учитывать мнение граждан. Более долгосрочные меры по достижению национальных целей будут определяются в рамках отраслевых стратегий, которые затем в рамках бюджетного цикла конкретизируются в национальных проектах и государственных программах. Для обеспечения оперативной гибкости единый план будет корректироваться один раз в год.

Понятно, что реализация представленных изменений не возможна без цифровизации государственного и муниципального управления. Главным ресурсом планирования становятся данные в цифровом виде, обработка больших объёмов информации и использование результатов их анализа (аналитика) в государственном управлении. Ключевым инструментом цифровизации будет цифровая аналитическая платформа (ЦАП) - часть Национальной системы управления данными, которая охватит все органы власти. Процесс формирования национальной системы управления данными займет пять лет, с 2019 г. до 2024 г. Уже сегодня реализованы отдельные ее элементы, позволяющие проводить мониторинг реализации устойчивого развития страны и регионов,- это, например, BusinessIntelligence (ВI-система) Росстата [2] и автоматизированная система «іМониторинг», мобильное приложение «iMonitoring» [8].

BI- платформаРосстата предназначения для публикации официальной статистики в широком доступе. Это первое в мире применение такой технологии для публикации и представления официальной статистической информации. Набор статистических показателей будет состоять из 70 важнейших тем социально-экономической статистики. Информация отражается в виде интерактивной таблицы, графиков и географических карт. Теперь на веб-странице Росстата стало возможным выполнять OLAP-операции: «углубляться» и «обобщать» данные, производить фильтрацию по произвольной совокупности параметров, «поворачивать» таблицу. У сотрудников ведомств, аналитиков, студентов, журналистов появится возможность использовать современные аналитические технологии бесплатно. Устанавливать дополнительное программное обеспечение для создания интерактивных отчетов не требуется. Результаты манипуляций могут выгружаться в MS Excel, PDF-форматах. BI позволяет вставлять интерактивные отчеты или их фрагменты - таблицы, графики или карты - в контент других веб-страниц. Благодаря чему данные будут обновляться при обновлении с сайтом Росстата.

Автоматизированная система «іМониторинг» - инструмент для оперативного мониторинга, в котором есть возможности процессов стратегического планирования в регионе с участием населения. Позволяет определить основные приоритеты, цели, задачи, мероприятия и показатели развития субъекта РФ или муниципального образования.

Мобильное приложение для государственного и муниципального управления iMonitoring содержит актуальную официальную информацию о финансовой и социально-экономической ситуации в России.

В заключении статьи отметим, что для использования внедряемых цифровых платформ в государственном стратегическом планировании и управлении необходимы квалифицированные кадры, которые смогут воспользоваться всеми преимуществами цифровизации. Также, требуется единообразие в создаваемых «цифровых» стратегических документах. 


\section{Библиографический список}

1. Антипин И. А. Цифровизация как инструмент трансформации стратегического развития территории//Теория и практика общественного развития, 2018., № 12 (130). С. 90-94.

2. BI-Portal Росстата [Электронный ресурc]: URL: http://bi.gks.ru/biportal/contourbi.jsp?allsol=1 \&solution=Dashboard (дата обращения: 20.05.2021).

3. Годовой отчёт о ходе реализации и оценке эффективности государственной программы Российской Федерации «Информационное общество (2011-2020 годы)» [Электронный ресурс] // Министерство цифрового развития, связи и массовых коммуникаций Российской Федерации. URL: https:/digital.gov.ru/uploaded/ files/otchet2016.pdf (дата обращения: 18.05.2021).

4. Государственное стратегическое планирование: состояние, перспективы и пути развития. [Электронный ресурс]: сборник аналитических материалов фракции политической партии Справедливая Россия в Государственной Думе Федерального собрания российской Федерации, 2020. URL: http://duma.gov.ru/media/ files/zAj1sCiOSaIA2xun8YQ5StZUYMXy5r6d.pdf (дата обращения: 18.05.2021). C.6

5. Джон Кеннет Гэлбрейт. Новое индустриальное общество. М. - Сб.: Из-во «Транзит-книга», 2004,602 с.

6. Исаева Н.И. Система прогнозирования и стратегического планирования республики Беларусь // В сборнике: Collection of scientific articles. Science editor: Ph.D. in Economics, Associate Professor, Professor of RANH Drobyazko S.I., 2015. С. 58-61. С.61

7. О национальных целях и стратегических задачах развития Российской Федерации на период до 2024 года: Указ Президента РФ от 07.05.2018 № 204 (ред. от 19.07.2018). [Электронный ресурс]: URL: http://www.pravo. gov.ru (дата обращения 16.05.2021).

8. Платформа iMonitoring [Электронный ресурс]: URL: https://www.iminfin.ru/ (дата обращения: 20.05.2021).

9. Программа «Цифровая экономика Российской Федерации»: утв. распоряжением Правительства РФ от 28 июля 2017 г. № 1632-р. [Электронный ресурс]: URL: http://government.ru/docs/28653/ (дата обращения 16.05.2021).

10. Проект единого плана по достижению национальных целей развития Российской Федерации на период до 2024 года и на плановый период до 2030 года. [Электронный ресурс]: URL: https://strategy24.ru/rf/ news/proekt-edinogo-plana-po-dostizheniyu-natsionalnykh-tselei-razvitiya-rossiiskoi-federatsii-na-perioddo-2024-goda-i-na-planovyi-period-do-2030-goda (дата обращения: 20.05.2021).

11. Стратегия развития Росстата до 2024 г.: утв. распоряжением министра экономического развития РФ от 06 сентября 2019 г. № MO-104. [Электронный ресурс]: URL: https://rosstat.gov.ru/storage/mediabank/Strategy. pdf (дата обращения 11.05.2021).

12. Усачев В.В. Законодательные аспекты регулирования системы государственного стратегического планирования в Российской Федерации// ЭКОНОМИКА И УПРАВЛЕНИЕ. N 12 (50) 2009. С. 7. С. 7-8.

13. Федеральный закон от 28 июня 2014 № $172-Ф 3$ «О стратегическом планировании в Российской Федерации» [Электронный ресурс]: URL: http://www.consultant.ru/document/cons_doc_LAW_164841/ (дата обращения 11.05.2021).

14. Цифровая экономика: глобальные тренды и практика российского бизнеса [Электронный ресурс]: электрон. изд. / отв. ред. Д. С. Медовников. URL: https://imi.hse.ru/data/2017/10/06/1159517769/! Цифровая\%20 экономика\%20-\%20глобальные\%20тренды\%20и\%20практика\%20российского\%20бизнеса.pdf (дата обращения: 20.05.2021).

15. Bublik Nikolaj Dmitrievich, Lukina Irina Ivanovna, Chuvilin Denis Valer'evich, Shafikov Timur Ajratovich, Junusova Razilja Fanuzovna The development of the digital economy in the regions of Russia: problems and opportunities (on the example of the Republic of Bashkortostan). Regional economy and management: electronic scientific journal. № 1 (53). Art. \#5313. Date issued: 2018-03-15. Availableat: https://eee-region.ru/article/5313/

16. Hamilton, Daniel S. The Transatlantic Digital Economy 2017: How and Why it Matters for the United States, Europe and the World Washington, DC: Center for Transatlantic Relations, 2017. 